facilities that can support the project; everything from removing the rock to ground support, service installation and surface infrastructure.

What is the final objective? The collaboration likes to see that the economic and operational success become mainstream. It is the intention to really develop and prove that it cannot only compete with drill and blast, but ultimately improve on it. When developing around sensitive areas where one requires low disturbance, hard-rock cutting will be important, as it will be in highly seismic ground. Then, if the unit cost of operating these machines gets low enough, one can start to assess orebodies that were previously not viable. At the same time, it is an electrified process so enables the industry to accelerate some of the decarbonisation plans for underground mining.

\title{
THE FUTURE
}

\section{Thermal coal in 2021}

According to IEA's recent December, 2020 report, the overall decline in global coal demand in 2020 has turned out to be lower than was estimated in the early months of the year as the pandemic spread and intensified around the world. This can be attributed to a smaller decrease in global electricity demand than was predicted earlier in the year and to the robust economic recovery in China, where more than half of global coal is consumed. Global coal consumption is estimated to have fallen by $7 \%$, or over 500 million tonnes, between 2018 in 2020. A decline of this size over a two-year period is unprecedented in IEA records, which go back as far as 1971 . Based on the assumption of a global economic recovery in 2021, we expect both electricity demand and industrial output to increase. As a result, we forecast a rebound in global coal demand of $2.6 \%$, led by China, India and Southeast Asia. Higher natural gas prices and electricity demand are set to slow the structural decline of coal use in the European Union and the United States, which both might their coal consumption grow for the first time in nearly a decade.

\begin{tabular}{|l|c|c|c|c|c|c|}
\hline & \multicolumn{3}{|c|}{ Values } & \multicolumn{2}{c|}{ Year-over-vear change } \\
\hline & $\mathbf{2 0 1 9}$ & $\mathbf{2 0 2 0 E}$ & $\mathbf{2 0 2 1 F}$ & $\mathbf{2 0 1 9}$ & $\mathbf{2 0 2 0 \mathrm { E }}$ & $\mathbf{2 0 2 1 \mathrm { F }}$ \\
\hline Coal-fired generation (million MWh) & 959.9 & 762.5 & 916.5 & - & $-21 \%$ & $20 \%$ \\
\hline Electric power coal burn (million tons) & 539.4 & 432.8 & 522.4 & - & $-20 \%$ & $21 \%$ \\
\hline Total U.S. coal production (million tons) & 705.3 & 524.9 & 624.5 & - & $-26 \%$ & $19 \%$ \\
\hline Natural gas-fired generation (million MWh) & $1,474.50$ & $1,516.30$ & $1,292.00$ & - & $3 \%$ & $-15 \%$ \\
\hline Henry Hub spot price for natural gas (\$/MMBtu) & $\$ 2.57$ & $\$ 2.07$ & $\$ 3.13$ & - & $-19 \%$ & $51 \%$ \\
\hline
\end{tabular}

Generation, consumption and prices. Source: EIA
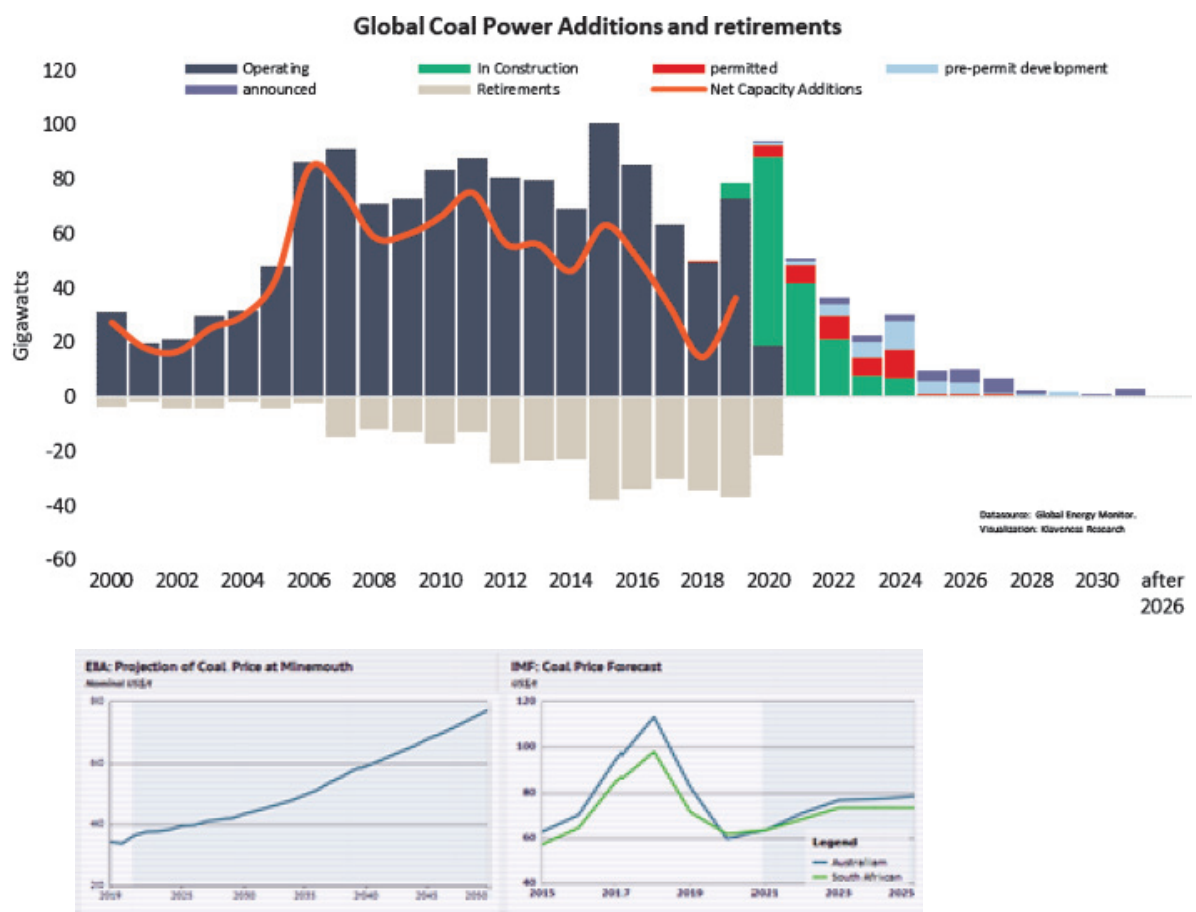

2014202020212022202320242

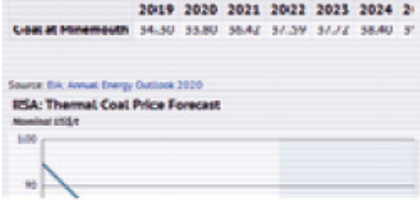

Source: knoema.com

20152014201720142010201020014
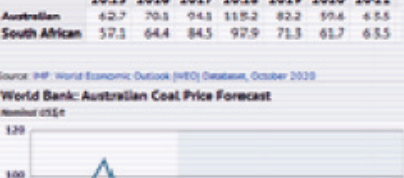

For better image, please see this link: https://knoema.com/xfakeuc/coal-priceforecasts-long-term-2021-to-2030-dataand-charts 